Hardie to complete their reports upon the yellow fever epidemic of 1878 , for the use of Congress.

In the house, a committee with similar powers and scope to those of the senate has been asked for by Young of Tennessee, and Cox of New York, and will probably be appointed at an early date.

- Dr. Jas. F. Harrison, of Virginia, has petitioned Congress for the removal of his political disabilities.

\title{
ST. LOUIS.
}

- A case of hernia vaginalis anterior, with an operation resulting in a radical cure, was reported at the last meeting of the St. Louis Medical Society. It is thought that there is no similar case on record. The woman was about twenty-five years of age. She had given birth to two children. The hernia came down, a little in front of the neck of the womb, into the vagina, occasionally protruding from two to three inches beyond the vulva. It was diaphanous, and its contents were easily recognized as a loop of the small intestines. Dr. G. M. B. Maughs, of this city, was called to see the case by Dr. Paul F. Eves. Sims's operation of elytrorrhaphy for procidentia was performed by Dr. Eves, who then left the city. The irritation of the wound seems to have produced sympathetic coughing, for a cough at once set in, which prevented the union of the denuded surfaces. This measure was tried three times, however, but always failed from apparently the same cause. This plan having had a fair trial, and the woman feeling that she would die unless a successful operation was performed, Dr. Maughs carefully removed the mucous membrane which covered the hernia, denuded the wall of the vagina for about a quarter of an inch around the opening through which the intestines had descended, and also freshened about an eighth of an inch of the hernial canal. The freshened surfaces were then joined by a quill suture, placed transversely to the axis of the vagina; the surfaces brought in contact were nearly half an inch in width. Superficial sutures were also used. In about twenty-four hours the quill sutures suppurated out. (This was before the days of carbolic acid.) In ten or twelve days the superficial sutures were removed, and the patient discharged, well. Seven years afterward Dr. Marion Sims saw the case, and took full notes of it. The woman was in perfect health; since the operation she had given birth to two children, and the only evidence of her former affliction was a narrow white line crossing the anterior wall of the vagina.

\section{SANTA BARBARA, WITH REMARKS ON CALIFORNIA. ${ }^{1}$}

Mr. Editor, - Having passed the last winter in Santa Barbara, I had an opportunity of witnessing the wonderfully beneficial influence of the openair life in that region upon invalids, especially consumptives, though the rainy season was one of exceptional severity. There is, however, urgent need of more careful discrimination by the profession in sending cases thither. I knew a young gentleman sent out by a leading surgeon of Philadelphia. He left a wife and child, and went alone, though in an advanced stage of consumption.

1 Read before the Suffolk District Medical Society. 
He bore the journey badly, and after a life of misery there hastened home. I knew a gentleman sent thither by a distinguished Fellow of this society. $\mathrm{He}$ too was far gone in consumption, and should never have left his home. As a rule, patients should go early in the course of their disease, and be prepared to make a long stay. But I do not wish to be understood as advising that no hopeless cases be sent. There are exceptional instances in which one has independent financial means, and can be accompanied by those most dear to him, so as to have the comforts of a home; then life may be prolonged, and death made easy. It is difficult to define a hopeless case, for many which are apparently hopeless will recover there. But it is certain that many go to their own injury, and the profession should pay more attention to the patients' circumstances aside from their physical condition.

During the winter more than thirty inches of rain fell in the town of Santa Barbara, and several inches more in the country around. Two years of drought had preceded these rains, and caused much poverty. The adobe houses of the Spaniards, when properly built, with verandas and cemented floors, are wellsuited to this semi-tropical climate. But many of these houses are not properly built. From these causes diphtheria and typhoid fever prevailed extensively among the poorer Spaniards, but, I believe, were exclusively confined to that part of the population. In a newspaper published in Santa Barbara, of which a copy has just reached me, is given the testimony of physicians and others as to the unusual physical development of children, and their freedom from diseases, especially croup and gastro-intestinal affections. My observations confirm these statements. There are in Santa Barbara well-educated and reliable practitioners of medicine. There are others who are both ignorant and unscrupulous. Having known most deplorable results from the frequency with which patients fall into the hands of the latter class, I recommend that physicians in sending patients thither assist them in advance in the choice of their future medical attendant. Well-qualified pharmacists, with well-appointed drug stores, are to be found, but, as in the choice of a physician, one must be on his guard against gross incompetency.

If I were to return to Santa Barbara, I should go by way of the Chicago, Burlington, and Quincy route from Chicago to Council Bluffs, from Omaha to Ogden by the Union Pacific, and from Ogden to San Francisco by the Central Pacific. The train moves very slowly across the plains and alkali desert, and the journey from Boston to San Francisco now occupies seven days. Arrangements are expected soon by which the journey will be made in six days. To go by Pacific mail steamships is somewhat less expensive. The journey from San Francisco to Santa Barbara, two hundred and eighty miles, is made on the coastwise steamers, of which the most comfortable are the Orizaba, Senator, and Ancon (side-wheeler). One will add materially to his comfort by providing himself with a hamper of eatables for the trip along the coast.

The city of Santa Barbara nestles down in a valley between the Santa Ynez range of mountains, with their foot-hills, and the sea. It is forty miles from Point Concepcion, and thirty from the town of San Buena Ventura. It is built on an inclined plain, which slopes upward from the sea and faces nearly 
directly southward. Snow never crosses the green foot-hills into the little valley, and frost is rarely known. The two predominant native trees are the live-oak, which dots the neighboring hills, and the sycamore. The eucalyptus globulus, the so-called blue-green tree of Australia (though it really came from Tasmania), has been planted in and about the town, and grows with astonishing rapidity. Roses bloom luxuriantly the year round, callas in thick clusters, the showy Pampas plumes, and various tropical trees. I have never seen elsewhere such handsome fuchsias.

When I visited Santa Barbara, in the winter of 1877-78, the population was estimated (perhaps overestimated) at six thousand, - four thousand whites, the rest Spaniards, Mexican half-breeds or "greasers," and Chinese. In 1870 there were thirty-five white inhabitants, and the town was almost unknown east of the Rocky Mountains. Santa Barbara is a winter resort. The rainy season begins usually in October or November, and continues till May. The average rain-fall is fourteen inches. The rain brings out the rich verdure, and in the intervals between the rains one can enjoy the bright, sparkling weather. I have bathed in the sea every month of the rainy season, from December to May inclusive. At the end of the rainy season come the fogs, lasting throughout the forenoon, or more rarely all day. Then the invalids depart to visit the magnificent Ojai valley, carpeted with a rich flora, to the Yosemite, or to their homes. The chief amusement is horseback riding. A well-trained mustang can be obtained at any time for twenty-five or thirty dollars. They are controlled by the Spanish bit, often cruelly abused. Barley enough to feed him a month can be obtained for six dollars. Except occasionally, in the wettest weather, the roads are excellent. The Arlington Hotel is a commodious and well-kept house, so constructed as to give the largest possible number of sunny rooms. In California a sunny room is essential to health and comfort. The contrast between sunshine and shade is very marked. The charges at the Arlington Hotel are moderate. If one chooses to keep house he will find it costs about the same as here to supply a table. Groceries cost double what they do here; meats, including game in season, are sold at a moderate price, and vegetables are very cheap. Vegetables are raised in an Italian garden, but are commonly obtained from Chinamen, who bring them to the door. I know a family of three whose table is plenteously supplied with vegetables for seventy-five cents a week. There are good schools, public and private, churches of various denominations, two banks, and a theatre, owned by Signor Lobero, a retired Italian opera manager. The climate of Santa Barbara is most equable, the difference between the highest and lowest temperature in the year being but forty degrees of Fahrenheit. This equability is doubtless due to its proximity to the sea and its sheltered position. The coast range shelters it from cold northerly winds, while the Santa Barbara Islands protect it from the opposite quarter. In the coldest weather a small wood fire is necessary morning and evening. It would perhaps be proper to speak of the climates of Santa Barbara. Some invalids will do best near the Mesa, a table-land near the sea. Others find higher and dryer localities more beneficial. Immediately after sunset a cold wave of atmosphere occurs, and continues about an hour, to be followed by greater warmth. There is no malaria in the town or its environs. 
The bathing season begins in May and continues all summer. The bathing facilities are excellent. Connected with one of the bath-houses are convenient arrangements for sun-baths, and I have known a tuberculous patient to derive much benefit from them.

The Spanish women are usually attended in confinement by midwives. Some of my medical friends were called late to one of these cases. The membranes had long been ruptured; a shoulder presented, and was crowded into the pelvis. They succeeded in performing version, but the child was dead. The Spaniards are strongly opposed to post-mortem examinations.

The best description of Santa Barbara ever published is from the pen of Albert F. Webster, and appeared in Appleton's Journal. Santa Barbara as a health resort has its disadvantages. It is a long distance from an Eastern home, - longer than the visitor may realize till he has made the journey. For eight days during the past winter communication by mail with the East was interrupted, and during a shorter period by telegraph. Occasionally a dust storm arises, which is intensely disagreeable. I have known a few raw, windy days, much like our own March weather. The opportunities for shopping are very inferior, and many persons obtain their clothes, even boots and shoes, by mail from the East. The prevailing diseases on the Pacific coast seem to be rheumatism, neuralgia (especially sciatica), and nasal catarrh. A friend, for the last twelve years an oculist in San Francisco, tells me he has met in his practice a large proportion of cases of episcleritis. A physician of San Buena Ventura, and lately of Philadelphia, finds uterine disease exceedingly prevalent, and attributes its frequency chiefly to too early rising after parturition. The same class of diseases appear to be common in San Francisco and Oakland, and in those cities criminal abortions and the employment of midwives must be powerful factors in their production.

My knowledge of California is chiefly derived from visiting four places, differing widely in climate and the character of their inhabitants: San Buena Ventura, the centre of au agricultural region, with a settled population; Santa Barbara, whose population is largely transient and invalid, and where the active interests of the place are rather horticultural than agricultural; San Francisco, a cosmopolitan city, whose climate in the spring and summer, when the trade-winds blow and the fogs roll in, is very severe; and Oakland, a city of residences, with a climate far milder than the neighboring metropolis.

Edward L. Parks.

\section{SHORT COMMUNICATIONS.}

\section{FRENCH QUARANTINE.}

A. Sanitary Measures applicable to the Prevention of the Plague at the Mediterranean Ports. -(1.) Suspected vessels (Article 36 of General Directions) - that is to say, having no actual case of plague on board during the voyage - are submitted to a quarantine in a lazaret. For these cases a quarantine of observation of five to ten entire days, either in the lazaret or on board of the troop-lazaret, is insufficient. The unloading, the disinfection of wearing apparel or of materials susceptible of retaining infection, is obligatory. The quarantine of persons remaining on board during the discharge of the cargo is from five to ten days, and does not commence until after the disinfection of the ship is terminated. (2.) For vessels 